and only 7 had been obliged to seek lighter employment; of 7 operated patients only 2 are fully capable of working. In the reference to Dr. Boysen's review ${ }^{2}$ some significant figures have been omitted : $86.5 \%$ (225 out of 260 ) have complete working capacity, while 30 are fit for light work. Only 5 are unable to work. These figures agree with those of Kuhns," who found that 790 out of 1,000 patients recovered completely from sciatica without operation.

If, as Prof. Jefferson emphasizes, the clinical picture of disk protrusion does not differ at all from that of the cases in which no protrusion was found at operation, it is possible that the pain is not due to the protrusion. This possibility is strengthened by the recent demonstration that complete recovery is the rule after a negative exploration of the lumbosacral canal. ${ }^{45}$

Most of the optimistic reports of operation on intervertebral disks are based on surveys conducted by questionary. We should welcome, therefore, the recent appearance of two reports based upon the physical examination of the patients by practitioners who had not performed the operation : (i) Aitken and Bradford $^{6}$ : results good in 50 out of 170 cases; $45 \%$ unable to return to work. (ii) Lenhard ${ }^{7}$ (reviewing the work of the late W. E. Dandy) : only 35 out of 147 are entirely well.-I am, etc.,

Melbourne.

Michael Kelly

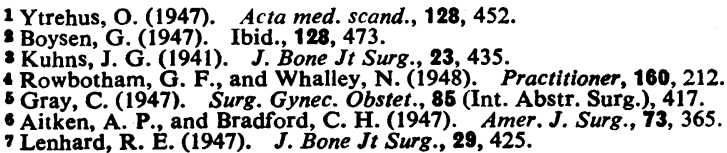

\section{Termination of Pregnancy}

SIR,-Women desirous of having their pregnancies terminated on psychiatric grounds generally fall into one or other of the following groups : $(a)$ the frankly neurotic ; $(b)$ those who have previously had a psychotic illness; $(c)$ the pre-menopausal, often associated with $(a)$ or $(b) ;(d)$ the unmarried; $(e)$ the married, with as many children as they can reasonably manage (inadequate housing, economic factors, etc., constitute very real problems in this group); $(f)$ those who attempt to evade their normal and natural responsibilities on some frivolous pretext. The syndromes presented by each group are fairly constant for that group. Each case should be decided on its merits, and it is important to obtain as much corroborative evidence as possible before reaching a decision, which, as Dr. Chesser so aptly puts it (June 5, p. 1110), is " practically always a choice between a greater and a lesser evil."

Childbirth is the natural function of women, and any reluctance on a woman's part to carry on with a pregnancy must be viewed with concern. We should not think merely in terms of a condition reactive to an unwanted pregnancy. If we do so we may fail to identify a deep-seated disorder, which may involve the patient in a mental breakdown whether her pregnancy is terminated or not. The most difficult cases to assess are the unmarried women with stable past histories. The social and economic consequences of having an illegitimate child obviously have more violent repercussions upon them, by and large, than does the advent of an unwanted child to a married woman. The unmarried unwillingly pregnant woman frequently commits suicide, while her married contemporary rarely does so.

As previously mentioned, the acute disturbance precipitated by an unwanted pregnancy may readily obscure a serious disorder of personality. The relief afforded by a therapeutic abortion tends to produce a false sense of security in such cases. Before reaching a decision, therefore, on the desirability of terminating a pregnancy, a comprehensive psychiatric investigation is called for, preferably spread over a number of interviews. It has been difficult in the past to insist on further treatment after the surgical interference has been concluded. but with the advent of the National Health Service psychiatric treatment should be available to patients who formerly could ill afford it. Psychological treatment is as important after therapeutic abortion on psychiatric grounds as is the re-education and rehabilitation of a patient after amputation.-I am, etc.

London, W.1.

Ellis Stungo.

\section{Stiff Test for Nurses}

SiR,--In connexion with the current discussion on the training of nurses I should like to draw attention to certain questions in the fevers paper recently set for the Final State Examination of the General Nursing Council.

1. "Which infectious diseases may be complicated by involvement of the central nervous system ; what are the special risks and how may the diagnosis be confirmed ?"

2. "Describe the appearance, cultural characteristics, and properties of the diphtheria bacillus."

Apart from the scope, ambiguity, and complexity of the first question, there arises an important point of definition. In regard to the second question an adequate answer would involve a knowledge of bacteriology quite beyond that which should be required from student nurses. In fact, the Council's syllabus merely refers to the "causation" of diphtheria, and a standard textbook in popular use among nurses deals with the subject in a few lines.

Questions such as these produce a sense of frustration and not unreasonable indignation among candidates. As one responsible for the training and recruitment of nurses I suggest that the requirement of such academic standards of medical and bacteriological knowledge does not tend to produce or discover good practical nurses, nor does it help to overcome existing difficulties in regard to nursing shortage and lack of recruits to the profession.-I am, etc.,

Ilford.

J. H. WEIR.

\section{Convalescent Homes}

SIR,-We see all round us the deplorable results of sectionalism, both at home and in the international field. In a small way we may combat this evil by taking care that it is not made part of medical planning. I have been struck by the opportunities presented when patients are sent away to convalesce.

Recovery is inevitably assisted by stimulating surroundings and contacts. It is therefore regrettable that in so many places convalescents are collected from one small occupational group, whereas if persons in a variety of different employments were brought together they would, from the very diversity of their interests, stimulate one another while broadening their minds. In this way some little may also be done to remove those distrusts and animosities which derive from a narrow and restricted way of life. For these reasons it appears desirable to make the most of an opportunity to secure on the same occasion a more rapid physical and mental recovery with, as one may hope, an increase in social and political sense. -I am, etc.

Hadley Woods, Herts.

G. C. Pether.

\section{Short Leg in Soldiers}

SiR,-We read with interest Dr. Nesta $H$. Wells's letter (June 19, p. 1206) on scoliosis in school-children and her plea for early compensation for leg shortening by heel raising. In dealing with recruits in the Army who are sent to the Army Physical Development Centre we have found a high incidence of leg shortening with resultant scoliosis. The recruits sent here are mostly in the $17 \frac{1}{2}-18 \frac{1}{2}$-years age group. The shortening varies from $1 / 4$ in. to 11 in. $(0.63 \mathrm{~cm}$. to $3.17 \mathrm{~cm}$.). Remarkably few give any history of backache, sciatica, or bony injury to the lower limbs, or of poliomyelitis. Even fewer are aware prior to our examination that there is any shortening.

It is our practice, however, whether symptoms are present or not, to compensate for shortening by heel raising as a prophylactic measure against back pain, except where the shortening is $1 / 4 \mathrm{in}$. or less. Such shortening we regard as a normal variation. In all cases where symptoms are present, and especially in youths of this age group, it is most important that other causes of low back pain, including ankylosing spondylitis. are ruled out. We therefore make it a rule in these cases to have an $x$-ray examination of the spine and sacro-iliac joints.

Shortening of between $1 / 2 \mathrm{in}$. and $1 / 4 \mathrm{in}$. we treat by raising the heel on the affected side by that amount. Heel raising of more than $1 / 2$ in. gives rise to a somewhat cumbersome boot. Therefore. when the shortening is of more than $1 / 2$ in., we find 
it more satisfactory to raise the heel on the affected side by half the required amount and to lower the heel on the opposite side by a corresponding amount. We have found that few of these young soldiers feel any awkwandness or discomfort from boots altered in this manner ; in fact most of them say that they now feel more comfortable. When the boots have been satisfactorily adapted we impress upon these youths the desirability of maintaining these alterations throughout their service and on return to civilian life.

We are deliberately omitting any statistics, as we feel that the recruits sent here are not a true cross-section of young adults, since they are specially chosen to attend a remedial course for various postural or other defects at this physical development centre.-We are, etc., No. 1 Physical Development Centre
Chester.
ROBERT FULLER, Capt., R.A.M.C Lieut., R.A.M.C. Graded Specialist in Physical Medicine.
Douglas L. Woolf,

\section{The S.R.M.}

SIR,-In the interests of accuracy may I point out that the principal point of Dr. Holman's letter under the above heading is founded on a mishearing or misconception? The proposal, duly seconded, from the body of the Great Hall and accepted by the Chairman, and approved by vote of the majority by a show of hands, was "that the meeting pass to the next business." In a short subsequent discussion, from the body of the Hall, this was agreed as intending to pass by all the motions of censure on the Council-but not those applying to censure of the Editor of the Journal. The first of the motions referring to the Editor was moved, spoken to by several speakers, and rejected by a huge majority. Of course 1 do not know what the Chairman said to Dr. Holman on the platform, but this was the actual sequence of events, my memory of which is perfectly clear.

In taking the action he did the Chairman was merely conforming to the wishes expressed by vote of the majority of the Representative Body.-I am, etc.,

Plymouth.

Cyril F. Mayne.

\section{Remuneration of General Practitioners}

SIR,-A leading article in The Times of May 15 comments on the Spens report with special reference to the remuneration of dentists, but the case of the general medical practitioner demands equal consideration. Since the Minister announced his terms of service last December general attention has been concentrated upon matters of principle, and the actual payment of doctors was not an issue in either plebiscite this year. Now that the B.M.A. has recommended the profession not to refuse co-operation in the Service the amount of remuneration becomes of immediate importance.

It should surely be conceded that acceptance of service under the Act ought not to involve a loss of income for the rank and file of the profession. But careful study of the Minister's proposals shows that grave financial loss may be caused to a high proportion of doctors who have hitherto owned mixed " panel " and private practices. It is becoming increasingly obvious' that, owing to the high compulsory National Insurance contributions and the heavy charge on income tax receipts to maintain the Health Service, most patients will feel unable to pay doctors bills in addition, so the amount of private practice remaining will generally be very small, and in most mixed practices the future income from this source will be negligible. Salaried appointments, such as district medical officers for public assistance and public vaccinators, will terminate, since all patients are to be placed on doctors' lists and compulsory vaccination ceases. The vast majority of general practitioners are thus likely to be almost entirely dependent upon capitation payments for National Health Service patients, and this being so the proposed capitation fee should be much increased. It must be remembered that the Spens recommendations were based on the pre-war cost of living and that their investigations were into the income and expenses of doctors during the years 1936-7-8. Since then every essential item of a doctor's professional expenses has greatly increased-sometimes (e.g. cars) by $100 \%$.

Two methods proposed for calculating fees are unjust. (1) The fewer the patients joining the Service the higher the capitation fee (15s. 2 d. for $95 \%$, increasing to $18 \mathrm{~s}$. for $80 \%$, of the population). This should be reversed, since the fewer there are in the Service the greater the potential income from private practice, and vice versa. (2) A central fund is proposed equal to a capitation fee of $18 \mathrm{~s}$. multiplied by $95 \%$ of the population. The first charges on it would be payment for mileage, temporary residents, emergencies, etc., and "inducements" or basic salaries. What is left becomes the general capitation fee. It would be better to settle a firm capitation fee first and pay other charges from a separate fund after.

The disastrous effects of the present proposals on doctors in a typical rural area can be shown by one concrete example. In a certain district of 9 parishes there is a population of 10,000 of whom 7,500 are concentrated in two adjoining villages. With the gross capitation fee of $18 \mathrm{~s}$. the income payable to doctors practising here would be $£ 9,000$, but with the more likely actual fee of about $15 \mathrm{~s}$. it would be $£ 7,500$. There are 10 general practitioners in this district, of whom 8 have mixed panel and private practices. If practice expenses are taken as. $25 \%$, the net income these dectors may expect would be $£ 5,625$ for a $15 \mathrm{~s}$. capitation fee rising to $£ 6,750$ for one of $18 \mathrm{~s}$. Even if one were justified in assuming that only 8 of these men were fully occupied, none of them could hope to earn as much as. $£ 1,000$ per annum. In none of these practices does the income received from present panel capitation fees amount to a quarter of the gross receipts, so the losses may thus amount to $50 \%$ of their present income. (The lower figure cannot allow for mileage payments, but the $18 \mathrm{~s}$. proposed by the Minister probably more than covers what may at present be expected.) This very disturbing example of the general practitioner's prospects could doubtless be multiplied throughout the country.

The changes by voting shown in the last plebiscite were undoubtedly prompted by economic pressure; but of those general practitioners voting $67 \%$ still disapprove of the Act and $53 \%$ were against accepting service. It is obvious that most of the profession will enter the Service with grave misgiving and the prospect of a serious drop in income and standard of living. The Service must inevitably cause harder work for doctors. It offers no payment for locums-the doctor must "provide a deputy"- -and no lessening of hours during which a man is liable for duty. When in every other walk of life higher wages are being paid for shorter hours, is it fair that doctors should receive so much less for more work, and under conditions of service which are still distasteful to so many ?-I am, etc.,

\section{RALPH GREEN,}

\section{Medical Education and the G.P.}

SIR,-Two committees have now recorded their recommendations for the reform of medical education. The latest report states that "the undergraduate curriculum .... can do no more than lay the foundation of a doctor's education : but it should stimulate him to remain a student all his life" (Journal, May 29, p. 1038). How, in the face of all the clerical work he must perform, can a G.P. remain a student ? I have heard of practices where the dispenser divides the waiting-room patients into $(a)$ those wanting certificates, $(b)$ those asking for medicine, and $(c)$ those demanding letters to visit the hospital " to be examined." How is this to be prevented when there is so great a temptation to allow it to spread under the N.H.S. ? The committee on postgraduate education which is to be set up may be able to tell us.

I would like to make the following suggestions :

(1) We attempt to divide the work so that the numbers of N.H.S. patients are between 1,500 and 3,000 per doctor.

(2) We try to maintain the clinical enthusiasm instilled into us by our specialist teachers. What G.P. can deny that feeling of satisfaction at detecting, for example, a patch of bronchial breathing in a feverish patient with pain in the chest?

(3) We give ourselves time to examine our patients and make at least a tentative diagnosis for all patients referred to a specialist. Surely this, if only from the mistakes we make, is how we shall learn. We may also help to cut down unnecessary investigations, the rising flood of which Dr. Ffrangcon Roberts justly deplores (March 13, p. 485). I like the story (told by one of my recent chiefs) of the Regular Army specialist replying to a brief, "Please examine and advise," with, "You examine and I will advise." 